\title{
"Does Modular Teaching Improve the Knowledge, Attitude and Practice related to Immunization among Medical Students?"
}

\author{
Kar, S.S. ${ }^{1}$, Ramalingam, A. $^{2}$ \& Majumdar, A. $^{2}$
}

\begin{abstract}
Introduction: The study evaluates the effect of modular teaching on the knowledge, attitude and practice of medical students related to immunization.

Methods: Departments of Microbiology, Preventive and Social Medicine and Paediatrics of a tertiary care teaching institution jointly designed and structured the module for the students. The students were evaluated using a retro pre questionnaire.

Results: 37 students returned the completed questionnaires. There was a significant increase in the knowledge, attitude practice and scores in the post test to the extent of $31.2 \%, 6 \%$ and $16 \%$ respectively.
\end{abstract}

Conclusion: Hence modular teaching methodology was found to be effective in learning immunization by MBBS students.

Keywords: immunization, medical education, modular teaching.

\section{Introduction}

Medical education is undergoing a rapid metamorphosis. As researchers are trying to explore innovative methods of teaching, the barriers to learning are being breached. Medical education in India is largely compartmentalised into basic sciences, paraclinical and clinical branches; this makes learning fragmented and difficult for students.

\footnotetext{
${ }^{1}$ Additional Professor

${ }^{2}$ Senior Resident

Department of Preventive and Social Medicine,

Jawaharlal Institute of Postgraduate Medical Education and Research (JIPMER)

Puducherry.

Corresponding Author:

Kar Sitanshu Sekhar

Additional Professor

Department of Preventive and Social Medicine

Jawaharlal Institute of Postgraduate Medical Education and Research (JIPMER)

Puducherry
}

Email:drsitanshukar@gmail.com
Problem solving in clinical cases and community scenarios involves understanding and assimilation of the principles of all branches of medicine related to the issue at hand. This can be achieved with the help of integrated teaching.

Recognising the importance of this, the Medical Council of India (MCl) has come up with "Regulations on Graduate Medical Education, 1997" which recommend horizontal and vertical integration of various subjects in the MBBS curriculum (Medical Council of India, 1997). Various countries have already developed guidelines and structured their curriculum based on the principles of integrated teaching; this includes the General Professional Education of the Physician report (Kirby, 1987) ACMI-TRI project report (Swanson \& Anderson, 1993) and recommendation of the General Medical Council, UK (General Medical Council, 1993). Even though evidence favours this method of teaching, it has still not become popular in medical colleges in India.

The immunization is one of the core areas where integrated teaching is warranted as it involves application of principles related to para-clinical and clinical subjects. Immunization Programme in India has undergone a number 
of significant changes in the recent years including a new policy environment, newer vaccines and newer technologies for vaccine delivery and cold chain maintenance. Immunization also belongs to one of the "must know" areas in the MBBS curriculum. It is therefore imperative to impart holistic knowledge about immunization to the MBBS students. Hence, it was decided to evaluate the impact of an immunization module using integrated teaching methodology on the knowledge, attitude and skills of VII semester MBBS students of a tertiary care teaching hospital.

\section{Methods}

A modular teaching programme on immunization was coordinated by the department of Preventive \& Social Medicine (PSM) with involvement of Microbiology and Paediatrics departments of one of the tertiary care institutions of national importance in Puducherry, India in the month of July 2013. A meeting of the representatives of the nominated departments was conducted and the objectives of the module were formed up. The session wise plan of the module was communicated to each of the facilitators (Table 1). A total of 6 hours were allocated over a period of three days as per the circular communicated by the Academic section of the Institute. The modular teaching activities were conducted in the post lunch session from 2:30 to 4:30 pm. This was the first modular session after the student vacation of the students.

The objectives of the "module" were to sensitize the participants to explain the importance and history of vaccination in India, immune response following vaccination, demonstrate routes of vaccination for various antigens and sensitize about the responsibilities of Medical Officers in routine immunization. As future medical officers, it is imperative for medical students to know both the technical and managerial aspects of immunization. It was decided to evaluate the impact of the module on knowledge, attitude and skills of participants using a retrospective pre then post design questionnaire. This is a popular method to assess learners' self-reported changes in different domains, takes little time, is minimally intrusive and avoids pre-test sensitivity and response shift bias. In this method information is collected only once, at the end of the programme.

A retro-pre questionnaire was developed addressing the knowledge, attitude and skill regarding routine immunization services provided in India. The participants were asked to rate their knowledge, attitude, skills and behaviour at the end of the programme and then reflect back and rate those same qualities before participating in the programme. Age and gender details of the participants were also collected. Scores were allotted to various categories. The three categories for 'Knowledge' were 'No idea', 'Have a vague idea' and 'Clear idea'. The score for 'No idea' was 0,1 for 'Have a vague idea', and 2 for 'Clear idea'. Eight areas were explored under the heading 'Knowledge', giving a total score of 16. For 'Attitudes' respondents' agreement with a set of three statements was explored using a Likert-type scale. The scores were: $5=$ strongly agree, $4=$ agree, 3 = no opinion, 2 = disagree and $1=$ strongly disagree with the statement. The scores for three statements were added to obtain the total 'Attitude' scores. The maximum possible score was 15. Four sets of 'Skills' were studied. For each skill the respondent was given the following choices: "he/she was not confident', 'somewhat confident', 'and very confident' in performing the skill and 'will be able to do independently in future'. These were given the scores of $0,1,2$ and 3 respectively. The total skills score was calculated adding the scores of the four skills. The maximum score was 12.

The median total 'Knowledge', 'Attitude', 'Skills', overall scores, and interquartile range were calculated. The data were analysed using SPSS version 20 for Windows. One sample Kolmogorov-Smirnov test was used to determine the normality of the variables. Most variables were found to follow a non-Gaussian distribution and hence non-parametric tests were used. Median scores before and after the module were compared using the Wilcoxon signed ranks test. A p value less than 0.05 was taken as statistically significant.

\section{Results}

A total of 87 MBBS students were present in the VIIth semester batch. Out of them, a total of 40 students attended all three days of the module. 37 students returned the completed forms out of 40. Students who missed even a single session were excluded from the analysis. The mean age of the students was $20.7 \pm 1.07$ and $51.3 \%$ were females. Table 1 describes the plan of the module which was conducted with involvement of three departments. 
Table 1: Plan of the immunization module

\begin{tabular}{|c|c|c|c|c|}
\hline Day & Session & Topics Covered & $\begin{array}{l}\text { Responsible } \\
\text { Department }\end{array}$ & $\begin{array}{l}\text { Time } \\
\text { allotted }\end{array}$ \\
\hline \multirow[t]{3}{*}{ Day 1} & Introduction & $\begin{array}{l}\text { Objective of the module, History of Immunization } \\
\text { Programme in India }\end{array}$ & PSM & $\begin{array}{l}30 \\
\text { minutes }\end{array}$ \\
\hline & $\begin{array}{l}\text { Immunology } \\
\text { Part I }\end{array}$ & $\begin{array}{l}\text { Basic Concepts } \\
\text { Process of developing Immunity }\end{array}$ & Microbiology & $\begin{array}{l}60 \\
\text { minutes }\end{array}$ \\
\hline & Open House & Interaction with students and doubt clarification & $\begin{array}{l}\text { PSM/ } \\
\text { Microbiology }\end{array}$ & $\begin{array}{l}30 \\
\text { minutes }\end{array}$ \\
\hline \multirow[t]{2}{*}{ Day 2} & $\begin{array}{l}\text { Immunology } \\
\text { Part II }\end{array}$ & The types of vaccine and their action & Microbiology & $\begin{array}{l}30 \\
\text { minutes }\end{array}$ \\
\hline & $\begin{array}{l}\text { Vaccination at } \\
\text { a hospital Set } \\
\text { up }\end{array}$ & $\begin{array}{l}\text { Visit to the Immunization Clinic. } \\
\text { Briefing at the clinic about UIP }\end{array}$ & Paediatrics & $\begin{array}{l}90 \\
\text { minutes }\end{array}$ \\
\hline \multirow[t]{2}{*}{ Day 3} & $\begin{array}{l}\text { Conducting } \\
\text { Vaccination at } \\
\text { Community } \\
\text { Set up }\end{array}$ & $\begin{array}{l}\text { Summary of previous day activities } \\
\text { Managerial functions of the MO } \\
\text { Group work: } \\
\text { - How to maintain cold chain? } \\
\text { - How to reach out to the un-reached? } \\
\text { during IPPI? } \\
\text { Adverse events following Immunization (AEFI) } \\
\text { Vaccine Preventable disease (VPD) surveillance }\end{array}$ & PSM & $\begin{array}{l}90 \\
\text { minutes }\end{array}$ \\
\hline & $\begin{array}{l}\text { Summary \& } \\
\text { Feedback }\end{array}$ & Summary of three days activity & PSM & $\begin{array}{l}30 \\
\text { minutes }\end{array}$ \\
\hline
\end{tabular}

There was a significant improvement in the scores for assessing knowledge $(p<0.001)$, attitude $(p=0.001)$ and practices $(p<0.001)$ of the study participants on completion of the module as compared prior to the start of the module (Table 2). The overall change in scores (assessed by taking the sum of scores in all the three domains i.e. knowledge, attitude and practice) was also statistically significant.

Table 2: Domain wise scores for knowledge, attitude and practice among the students

\begin{tabular}{llll}
\hline $\begin{array}{l}\text { Domain } \\
\text { (Range of possible } \\
\text { scores) }\end{array}$ & $\begin{array}{l}\text { Retro Pre } \\
\text { Median (IQR) }\end{array}$ & $\begin{array}{l}\text { Post } \\
\text { Median (IQR) }\end{array}$ & p value \\
\hline Knowledge $(0-16)$ & $7(4-9)$ & $12(11-14)$ & $<0.001^{*}$ \\
\hline Attitude (3-15) & $13(12-15)$ & $14(13-15)$ & $0.001^{*}$ \\
\hline Practice $(0-12)$ & $2(1-4)$ & $4(4-6)$ & $<0.001^{*}$ \\
\hline Total $(3-43)$ & $22(20-24)$ & $31(29-34)$ & $<0.001^{*}$
\end{tabular}

*: Significant (Wilcoxon signed rank test)

\section{Discussion}

It was found that there was a significant increase in the knowledge, attitude and practice scores in the post test of the participants to the extent of $31.2 \%, 6 \%$ and $16 \%$ respectively. Overall scores increased by $21 \%$ in the post test when compared with the retro pre scores. Few studies in India have assessed the impact of newer methods of teaching, like modular teaching and integrated teaching in the undergraduate medical curriculum. A similar study done in the same institution about a decade ago to evaluate two separate modular teaching programme on Leprosy found that both the modules had an increase of around $17 \%$ and $15 \%$ of scores in the post-test as compared to pre-test (Karthikeyan \& Thappa, 2003). Significant increase in the post-test scores were observed as compared to pre-test scores $(p<0.001)$ in a study done to assess the impact of modular teaching on Acute Respiratory Infections under the Integrated Management of Neonatal and Childhood Illness (IMNCI) Programme of Government of India (Srikanth et al., 2011). Other studies have 
reported that module based integrated teaching Programme had helped students in understanding and application of basic science knowledge to health and disease (Ghosh \& Pandya, 2008; Vyas et al., 2008).

One of the strengths of the study was the use of the retro pre questionnaire. Conventional pre and post assessment techniques have an intrinsic bias; this is because the respondents are already exposed to the questions in the pretest and this might influence the responses in the post test. Additionally pre- post assessment could lead to response shift bias. These biases are overcome by the use of a retro pre questionnaire. Low attendance and the assessment of practice component using scores rather than actual testing the skills were some of the limitations of this study.

Modular teaching for immunization led to significant improvement in knowledge, attitude and practice domains of students. Further studies must be done to test the feasibility of modifying the current medical curriculum on the basis of integrated teaching methods.

\section{References}

General Medical Council (1993) Tomorrow's doctors: Recommendations on undergraduate medical education, General Medical Council, London. Available at: http://www.gmcuk.org/Tomorrows_Doctors_1993.pdf_25397206. pdf [Accessed 21 September, 2013].

Ghosh, S. \& Pandya, H.V. (2008) Implementation of integrated learning Programme in neurosciences during first year of traditional medical course: perception of students and faculty, BMC Medical Education, 8,1, p. 44.

Karthikeyan, K. \& Thappa, D.M. (2003) Modular teaching Programme on leprosy, Indian Journal of Leprosy, 75,4 , pp. 317-325.

Kirby, R.L. (1987) The GPEP report on undergraduate medical education. Implications for rehabilitation medicine, American Journal of Physical Medicine \& Rehabilitation, 66, 4, pp. 184-191.

Medical Council of India regulations on graduate medical education (1997) Salient features of regulations on graduate medical education, $\mathrm{MCl}$, New Delhi. Available at: http://www.mciindia.org/RulesandRegulations/Gr aduateMedicalEducationRegulations 1997.aspx [Accessed 10 September, 2013].

Srikanth, S., Behera, B. \& Mahajan, P. (2011) Modular teaching: An alternative to routine teaching method for undergraduate medical students, Indian Journal of Community Medicine: Official Publication of Indian Association of Preventive \& Social Medicine, 36, 3, pp. 237-238.

Swanson, A.G. \& Anderson, M.B. (1993) Educating medical students, Assessing change in medical education-the road to implementation, Academic Medicine, 68,6, pp. S1-S46.

Vyas, R., Jacob, M., Faith, M., Isaac, B., Rabi, S., Sathishkumar, S., Selvakumar, D. \& Ganesh, A. (2008) An effective integrated learning Programme in the first year of the medical course , National Medical Journal of India , 21, 1, pp. 21. 